Conclusion 50\% of COPD patients requiring home ventilation were obese and $28 \%$ had diagnosed OSA. Although this study was a retrospective electronic record review, it suggests COPD-OSA Overlap Syndrome is common and underrecognised. OSA and COPD alone have RCT evidence supporting CPAP and NIV therapy; there is none in COPD-OSA. Given the high prevalence and mortality, it needs greater recognition as a discrete disease entity and urgent RCTs to establish optimum therapy, CPAP or NIV. Currently there is national variation in treatment based upon expert opinion and clinical availability. Yet there are significant cost differences and possibly different treatment efficacies. The majority of patients had NIV initiated in the outpatient setting, suggesting there would be time to arrange sleep studies to establish the COPD-OSA diagnosis prior to CPAP or NIV initiation. Given the high prevalence, should we be screening this high-risk cohort?

\section{P85 RESPIRATORY DEPRESSION IN OPIOID DEPENDENT CHRONIC OBSTRUCTIVE PULMONARY DISEASE PATIENTS}

${ }^{1} \mathrm{~B}$ Tas, ${ }^{1,4} \mathrm{NJ}$ Kalk, ${ }^{2,5} \mathrm{PSP}$ Cho, ${ }^{3} \mathrm{M}$ Lozano-Garcia, ${ }^{2} \mathrm{GF}$ Rafferty, ${ }^{4} \mathrm{M}$ Kelleher, ${ }^{2} \mathrm{~J}$ Moxham, ${ }^{1,4} \mathrm{~J}$ Strang, ${ }^{5,6} \mathrm{CJ}$ Jolley. ${ }^{1}$ National Addiction Centre, Institute of Psychiatry, Psychology and Neuroscience (IoPPN) at King's College London, London, UK; ${ }^{2}$ Division of Asthma, Allergy and Lung Biology, King's College London, London, UK; ${ }^{3}$ Biomedical Signal Processing and Interpretation group, Institute for Bioengineering of Catalonia (IBEC), Catalonia, Spain \& Biomedical Research Networking Centre in Bioengineering, Biomaterials and Nanomedicine (CIBERBBN), Barcelona, Spain; ${ }^{4}$ South London and Maudsley NHS Foundation Trust, London, UK; ${ }^{5}$ Centre of Human and Aerospace Physiological Sciences, King's College London, London, UK; ${ }^{6}$ King's College Hospital NHS Foundation Trust, King's Health Partners, London, UK

\subsection{6/thorax-2021-BTSabstracts.195}

Introduction In the UK, opioid-related deaths are at record numbers after continually increasing year-on-year (ONS, 2019). This increase is believed to be driven by an ageing cohort of people with Opioid Use Disorder (OUD) and a high prevalence of comorbidities including chronic obstructive pulmonary disease (COPD). Our previous findings suggest that the degree of acute opioid-induced respiratory depression is greatest in OUD patients with chronically-suppressed neural respiratory drive (NRD) as a consequence of drug misuse (Jolley et al.,2015). We investigated the severity of respiratory depression in OUD and tested whether OUD exhibit more severe respiratory depression than matched controls.

Methods A convenience sample of opioid addicts receiving treatment at a community Drug \& Alcohol Treatment Centre were recruited: OUD with normal lung function (OUD) and OUD with comorbid COPD (OUD-LD). OUD groups were matched with healthy controls (HC) and COPD patients with no history of drug/alcohol addiction (LD-Controls) from our laboratory database.

$\mathrm{SpO}_{2} \%$, end-tidal $\mathrm{CO}_{2} \quad\left(\mathrm{ETCO}_{2}\right)$, transcutaneous $\mathrm{CO}_{2}$ $\left(\mathrm{TcCO}_{2}\right)$, respiratory airflow and NRD index (NRDI), quantified using second intercostal space parasternal muscle electromyography (EMG $\left.\mathrm{G}_{\text {para }}\right)$, were measured continuously over 40 mins at rest. Significant respiratory depression was defined as: $\mathrm{SpO}_{2} \%<90 \%$ for $>10 \mathrm{~s}, \mathrm{ETCO}_{2}$ per breath $>6.5 \mathrm{kPa}$, $\mathrm{TcCO}_{2}$ overall mean $>6.5 \mathrm{kPa}$, respiratory pauses (absence of inspiratory airflow) $>10$ s.

Results Seven OUD patients (5M/2F, age: 48(46-52), $\mathrm{FEV}_{1} \%$ pred(\%): 96.1(90.5-96.5), FEV\%FVC(\%): 74.7(71.9-76.8)), 13 OUD-LD $\left(11 \mathrm{M} / 2 \mathrm{~F}\right.$, age: 49(42-55), $\mathrm{FEV}_{1} \%$ pred(\%): 77.1 (66.8-90.1), FEV\%FVC(\%): 60.2(48.7-64.3)), $7 \mathrm{HC}(6 \mathrm{M} / 1 \mathrm{~F}$, age: 50(45-57), FEV $_{1} \%$ pred(\%): 100(97.5-110.3), FEV\%FVC

\begin{tabular}{|c|c|c|c|c|c|c|c|c|c|}
\hline Number & $\begin{array}{l}\mathrm{SpO}_{2}<90 \% \\
>10 \mathrm{~s}\end{array}$ & $\begin{array}{l}\mathrm{ETCO}_{2} \text { breaths } \\
>6.6 \mathrm{kPa}\end{array}$ & $\begin{array}{l}\mathrm{TcCO}_{2}>6 \mathrm{kPa} \\
\text { mean }\end{array}$ & $\begin{array}{l}\text { Resp Pauses } \\
>10 \mathrm{~s}\end{array}$ & Number & $\begin{array}{l}\mathrm{SpO}_{2}<90 \% \\
>10 \mathrm{~s}\end{array}$ & $\begin{array}{l}\mathrm{ETCO}_{2} \text { breaths } \\
>6.6 \mathrm{kPa}\end{array}$ & $\begin{array}{l}\mathrm{TcCO}_{2}>6 \mathrm{kPa} \\
\text { mean }\end{array}$ & $\begin{array}{l}\text { Resp Pauses } \\
>10 \mathrm{~s}\end{array}$ \\
\hline \multicolumn{5}{|c|}{ OUD without LD: } & \multicolumn{5}{|c|}{ Healthy controls: } \\
\hline 1 & & $\checkmark$ & & $\checkmark$ & 1 & & $\checkmark$ & & \\
\hline $2^{1}$ & & $\checkmark$ & $\checkmark$ & $\checkmark$ & 2 & & $\checkmark$ & & \\
\hline 5 & $\checkmark$ & & & $\checkmark$ & 3 & & & & \\
\hline 8 & & & $\checkmark$ & $\checkmark$ & 4 & & & & \\
\hline 9 & & $\checkmark$ & $\checkmark$ & & 5 & & & & \\
\hline 16 & & $\checkmark$ & & & 6 & & & & \\
\hline $18^{1}$ & & $\checkmark$ & & $\checkmark$ & 7 & & & & \\
\hline \multicolumn{5}{|l|}{ OUD-LD: } & \multicolumn{5}{|c|}{ LD-controls: } \\
\hline $3^{1}$ & & & $\checkmark$ & & 1 & & & & \\
\hline $4^{1}$ & & $\checkmark$ & & & 2 & & & & \\
\hline $6^{1}$ & $\checkmark$ & $\checkmark$ & & $\checkmark$ & 3 & & & & \\
\hline $7^{1}$ & & & $\checkmark$ & & 4 & & & & \\
\hline $10^{1}$ & $\checkmark$ & & $\checkmark$ & & 5 & & & & \\
\hline 11 & $\checkmark$ & $\checkmark$ & & $\checkmark$ & 6 & & & & \\
\hline 12 & & $\checkmark$ & & & 7 & & & & \\
\hline 13 & & $\checkmark$ & & & 8 & & & & \\
\hline 14 & $\checkmark$ & $\checkmark$ & $\checkmark$ & $\checkmark$ & 9 & & $\checkmark$ & & \\
\hline $15^{1}$ & & & & $\checkmark$ & 10 & & $\checkmark$ & & \\
\hline 17 & & $\checkmark$ & $\checkmark$ & $\checkmark$ & 11 & & & & \\
\hline 19 & & $\checkmark$ & & $\checkmark$ & 12 & & & & \\
\hline 20 & & $\checkmark$ & & & 13 & & & & \\
\hline
\end{tabular}


(\%): 75(69.7-78.5)) and 13 LD-Controls (10M/3F, age: 66 (62-72), $\quad$ FEV $_{1} \%$ pred(\%): 60(52.8-74.5), $\quad$ FEV\%FVC(\%): 52 $(45-57))$ were studied. At least one of the respiratory depression indicators was detected in all 20 participants with OUD (Table1). Overall, there was a greater frequency of significant respiratory depression in both OUD groups compared to controls, most commonly $\mathrm{ETCO}_{2}>6.5 \mathrm{kPa} \quad(\mathrm{p}=0.021$; Table 1$)$. NRDI was significantly higher in LD-Controls than OUD-LD (217(43.7-504.5) $\mathrm{min}^{-1}$ and 148.5 (35-172.6) $\mathrm{min}^{-1}$, respectively $(\mathrm{p}<0.01))$, but there was no significant difference between OUD and HC (87.6(51.7-115.3) $\mathrm{min}^{-1}$ and 76.9 $(52.8-164.2) \mathrm{min}^{-1}$, respectively $\left.(\mathrm{p}=0.7)\right)$.

Conclusions Respiratory depression is frequently present in OUD patients with comorbid COPD and significantly more severe than in opioid-naïve controls. Further studies are required to determine the association between respiratory depression and overdose risk.

Please refer to page A193 for declarations of interest related to this abstract.

\section{COVID-19: clinical features and risk}

\section{P86 CHARACTERISING ANOSMIA IN HOSPITALISED PATIENTS WITH COVID-19}

${ }^{1} \mathrm{KF}$ Florman, ${ }^{1} \mathrm{M}$ Jayne, ${ }^{1} \mathrm{~A}$ Berezowska, ${ }^{1} \mathrm{E}$ Abouelela, ${ }^{2} \mathrm{~J}$ Hudson, ${ }^{1} \mathrm{~T}$ Al-Mayhani. ${ }^{1}$ Royal Free Hospital, London, UK; ${ }^{2} T$ he London School of Hygiene and Tropical Medicine, London, UK

\subsection{6/thorax-2021-BTSabstracts. 196}

Introduction Anosmia is one of the core symptoms of COVID-19, but its significance in hospitalised patients has not been extensively studied.

Aims Our aim was to characterise anosmia experienced by hospitalised COVID-19 patients, assessing whether subjective reporting correlated with examination findings which were quantified using our novel scoring system. We also looked to explore possible association between severity of anosmia and clinical outcomes, as well as whether severity correlated with comorbidities.

Method Over a two-month period we combined reported history of anosmia with olfactory nerve examination when assessing patients hospitalised with COVID-19. Examination included scoring patients on their ability to recognise distinctive smells of coffee, vinegar, clove, vanilla and mint from disguised bottles. A numerical grading system was established scoring severity of anosmia for each smell, with a total score calculated for each patient (table 1). Co-morbidities of all patients were noted and all were followed up at discharge to monitor whether they were admitted to intensive care (ICU) and whether they developed complications of COVID-19.

Results 46 patients were included, 33 (72\%) of whom were male. Examinations were either performed at admission in the Emergency Department or on medical wards shortly afterwards. $16(35 \%)$ patients were later admitted to intensive care. Mean length of stay was 21 days (SD 18.8). Coffee was the smell most often identified with a mean score of 1.09 (SD 1.13). Vinegar was least identified with a mean score of 1.8 (SD 0.89). There was a significant difference in patients' reporting of anosmia symptoms, compared to our objective assessment. $96 \%$ of patients (30 of 31) who reported no anosmia actually had objective evidence of anosmia on
Abstract P86 Table 1 Anosmia scoring system developed

\begin{tabular}{ll}
\hline Score for each smell & Meaning \\
\hline 0 & Able to identify the smell correctly \\
1 & Able to identify the smell but it doesn't smell right \\
2 & Unable to identify the smell \\
3 & Total anosmia \\
Total scores per patient & Definition \\
$0-4$ & Mild anosmia \\
$5-10$ & Moderate anosmia \\
$11-15$ & Severe anosmia \\
\hline
\end{tabular}

examination (test of proportion, $\mathrm{p}<0.001$ ). Severity of anosmia was not significantly associated with upper respiratory tract symptoms, ICU admission or development of complications from COVID-19. There was no correlation between severity of anosmia and presence of pre-existing comorbidities. Conclusion A significant proportion of patients studied were not aware they had anosmia. This has implications for pandemic management going forward when people are required to self-report this symptom and suggests potential benefit in formal examination of the olfactory nerve.

\section{P87 CLINICAL CHARACTERISTICS OF COVID-19 PATIENTS WITH PULMONARY EMBOLISM IN 1ST AND 2ND WAVES}

${ }^{1} \mathrm{AJ}$ Chung, ${ }^{2} \mathrm{MN}$ Dang, ${ }^{1} \mathrm{~T}$ Niaz, ${ }^{1} \mathrm{P}$ Palchaudhuri. 'Lewisham and Greenwich NHS Trust, London, UK; ${ }^{2}$ Imperial College London, London, UK

\subsection{6/thorax-2021-BTSabstracts. 197}

Introduction and Objectives Multiple studies have demonstrated increased risk of pulmonary embolism (PE) in COVID-19. Our study at a major NHS Trust examined the clinical characteristics, attributes and outcomes of PE in COVID-19, which have infrequently been explored in literature.

Methods We performed a retrospective cohort study of COVID-19 patients with PE diagnosed on CT pulmonary angiogram (CTPA) over 2 months in 1 st and 2nd waves (April 2020 and January 2021). Data collected from electronic health and imaging records included patient demographics, D-dimers, oxygen requirements, clinical outcomes, thromboprophylaxis/ treatment and PE attributes on CTPA.

Results We identified 76 COVID-19 patients with PE (mean age 62.2 years, $69.7 \%$ male, $40.8 \%$ Caucasian). Patients experienced prolonged periods of COVID-19 symptoms prior to PE diagnosis - 19.6 day symptoms in 1 st wave $(\mathrm{n}=16$, 21.9\%) compared to 15.2 days in 2 nd wave $(n=57$, $78.1 \%$ ). Average D-dimer was highly elevated (mean $=11576$ $\mathrm{ng} / \mathrm{mL}) .43(56.5 \%)$ patients had high oxygen requirements $21(27.6 \%)$ required $\geq 10$ litres/min via mask, 13 (17.1\%) required non-invasive ventilation and 9 (11.8\%) were intubated and ventilated. 22 patients $(28.9 \%)$ were admitted to intensive care and 11 patients (14.5\%) died. On admission, 48 patients $(63.2 \%)$ were started on treatment dose enoxaparin (high PE suspicion) and 12 (15.8\%) had intermediate (prophylactic) dose enoxaparin. PEs were largely treated with 3-6 months of rivaroxaban $(\mathrm{n}=43,56.6 \%)$ or apixaban (n $=7,9.2 \%) .65 .5 \%(\mathrm{n}=49)$ of patients had bilateral PEs; largest sizes being segmental $(\mathrm{n}=32,42.1 \%)$, subsegmental ( $\mathrm{n}=17,22.4 \%)$, lobar $(\mathrm{n}=16,21.1 \%)$, main pulmonary artery $(\mathrm{n}=5,6.6 \%)$ and saddle $(\mathrm{n}=5,6.6 \%) .15$ patients (19.7\%) had evidence of right heart strain on CTPA. 